\title{
Comparison of Dwell-Times of Two Commonly Placed Peripheral Intravenous Catheters: Traditional vs. Ultrasound-Guided
}

\author{
Gayla Miles, Patricia Newcomb, Dave Spear \\ Emergency Department, Texas Health Harris Methodist Hospital, Fort Worth, Texas, USA \\ Email: gaylamiles@texashealth.org
}

Received 10 November 2015; accepted 18 December 2015; published 21 December 2015

Copyright (C) 2015 by authors and Scientific Research Publishing Inc.

This work is licensed under the Creative Commons Attribution International License (CC BY).

http://creativecommons.org/licenses/by/4.0/

(c) (i) Open Access

\begin{abstract}
Introduction: Because establishing venous access in patients can be difficult and time consuming, the use of ultrasound to guide the insertion of peripheral intravenous catheters has become more common. Anecdotal evidence indicates ultrasound-guided catheter insertion may result in decreased catheter survival in the vein (dwell-time), but there is little evidence to support this observation. The purpose of this study was to compare dwell-times for peripheral intravenous catheters placed with ultrasound guidance with intravenous catheters placed by means of traditional anatomic insertion in patients in an acute care hospital. Methods: This secondary data analysis examined outcomes of 298 patients who received ultrasound-guided catheter insertion and 299 patients who received traditionally placed intravenous catheters. Multivariable linear regression was used to identify significant predictors of dwell-time for both the traditional and US-guided catheters. Results: The average dwell-times for ultrasound-guided and traditionally placed catheters were significantly different $(p<0.0001)$ with traditionally placed catheters surviving over twice as long as those placed with ultrasound guidance. The average dwell-time of traditionally placed catheters was 62.21 hours compared to 27.91 hours for catheters placed with ultrasound guidance. BMI, sex, age, and catheter insertion method were all significant predictors of dwell time $\left(R^{2}=0.22\right)$. Discussion: Dwell-times of catheters placed with ultrasound guidance are shorter than traditionally placed catheters. Ultrasound-guided catheters should be monitored closely for inadvertent removal or infiltration. A plan to place a more permanent type of intravenous access should be considered for patients admitted for patients longer than 24 hours.
\end{abstract}

\section{Keywords}

Ultrasound, Intravenous Catheter, Dwell-Time, Survival, Predictor, Ultrasound-Guided 


\section{Introduction}

Establishing venous access in patients can be difficult and time consuming [1]. The use of ultrasound (US) to guide the insertion of peripheral intravenous (IV) catheters has become more common in the last decade due to increasingly difficult venipunctures related to an aging population, obesity, and increasing co-morbidities [1]-[8]. Decreased time to cannulation, fewer venipunctures, and reduced disposition times are several benefits of using sonography to start IV's on patients with difficult access. Placing intravenous catheters with the aid of ultrasound rather than using traditional techniques may result in decreased costs and complications, as well [3]-[7]. As the Infusion Nurses' Society points out, ultrasound guided IV insertion has shown benefit, but the standard of practice in regard to this and other new techniques, such as infrared light technology, remains in development. More research is needed on the risks and outcomes associated with new intravenous devices and infusion approaches [1].

This study compares the IV catheter survival time between traditionally placed IV catheters and catheters placed using ultrasound guidance. The study occurred in a 750-bed, north Texas, urban, acute care hospital. The study hospital began a successful Registered Nurse-led peripheral ultrasound-guided intravenous (PUSGIV) insertion program in the emergency department (ED) in 2007. Since the program's inception, specially trained nurses at this hospital ED, insert approximately 7 PUSGIV's per day totaling approximately 3000 insertions annually. However, anecdotal evidence indicated that the survival (dwell-time) of PUSGIV catheters was shorter than the dwell-times of traditionally placed intravenous catheters (TPIV).

In acute-care hospitals, patients who are not deemed ill enough to require IV access are unlikely to be admitted. But for admitted patients, IV access is a critical aspect of care, regardless of the technique used to place an IV access device [1]. Without IV access of any kind, patient care and diagnosis are often delayed. Furthermore, complications related to IV's can cause permanent damage [9] [10]. Problematic access can result in transient complications or permanent damage. Monitoring and evaluation of every IV site are essential and care of the IV site, including regular changes of site and catheter, is a nursing responsibility [1] [9] [10]. The Infusion Nurses Society and CDC/HICPAC guidelines recommend that catheter replacement occurs every 72 - 96 hours to reduce the risk of infection and/or phlebitis, but the survival of an IV access device is variable and dependent on a number of factors, some of which are not known [10].

Being able to predict how long an IV catheter may remain in place without problems (dwell-time) is useful information for clinical staff. If the dwell-time of an IV is predictable, clinical staff can plan care accordingly [1]. Thus, pinpointing factors that influence dwell-time of IV catheters is clinically useful and important. Due to the importance of IV site management, identifying the true survival time of the PUSGIV catheter is pertinent and supports the need for nurses' knowledge regarding care of these catheters at the bedside.

\section{Literature Review}

A literature review was performed by the first author and a medical librarian using Medline and Cinahl databases. The review was limited to studies that described PUSGIV catheter survival among adults. Our search revealed 5 studies which met these criteria. Four of the 5 studies were conducted in ED environments where establishing intravenous access quickly is a high priority. Two studies evaluated PUSGIV catheter survival using a shorter catheter ranging from $4.5 \mathrm{~cm}$ to $6.35 \mathrm{~cm}$ without a guidewire for placement [7] [11]. The other three studies evaluated survival of central line length $(15$ or $16 \mathrm{~cm})$ catheters using guidewires placed by physicians (Seldinger Technique) [12]-[14]. In all of the studies of guidewire use, the placement of 15 or $16 \mathrm{~cm}$ catheters lasted longer than the shorter 4.5 or $6.5 \mathrm{~cm}$ catheters. But, in most nursing practice, nurses do not use guidewires to place longer catheters. The exception would be specially trained nurses who place PICC lines. Therefore, the two studies of non-guidewire approaches for IV placement were more relevant to our questions regarding dwell-times of shorter catheters used for peripheral intravenous access. This highlights the lack of existing evidence regarding dwell-times for PUSGIV catheters.

The PUSGIV catheter was introduced clinically approximately 15 years ago. In 1999, Keyes and colleagues published the first reports of using sonography to successfully place peripheral IV's in the basilic vein in patients with difficult venous access [15]. Over the past decade, nurses have increasingly incorporated into their practice the use of ultrasound to assist with IV insertion [1]-[3] [6] [8] [16]-[18]. Benefits have occurred because of this change in practice. The cost, time, and complications of central line insertion have been avoided in many cases, disposition times in the emergency department have been decreased due to the prevention of delay in 
treatment, and patient satisfaction scores have improved as patients receive fewer failed IV attempts using the PUSGIV approach [1]-[9] [15] [19]-[21].

Keyes and colleagues reported an 8\% PUSGIV catheter failure rate, mostly due to infiltration, in the first hour following catheter placement [15]. The failure rate of the PUSGIV catheter was theorized to be associated with shorter catheter lengths placed into the veins, especially in obese patients [15]. Approximately ten years later, after PUSGIV catheter insertions had become more common, two other studies were performed in 2010 and 2011. In 2010, Dargin and colleagues evaluated patients receiving 18 gauge, $6.35 \mathrm{~cm}$ PUSGIV catheters in an academic urban ED setting. The average survival time of the PUSGIV catheter was 26 hours, and approximately half of the inserted catheters (47\%) failed within the first hour [7]. In 2011, Fields and colleagues, also in an ED setting, evaluated the vessel depth, diameter, and location of placement of 20 gauge $4.5 \mathrm{~cm}$ catheters. Results showed the average PUSGIV catheter dwell time to be 48 hours with almost half (44\%) of the PUSGIV catheters remaining in working condition at that time [11]. Also, catheters placed in shallow vessels $(<0.4 \mathrm{~cm})$ survived longer. At 48 hours, neither investigative team compared dwell-times of PUSGIV catheters to traditionally placed IV catheters (TPIV).

Studies that focus on expectations for patients receiving different types of IV's, including TPIV, PUSGIV, PICC, midline, and central lines, are needed [1]. Because successful PUSGIV programs have become more common and the PUSGIV technique appears to be "here to stay"; and, because the technique fills a need in the clinical setting when an IV cannot be established by the traditional method, the dwell time of the PUSGIV catheters should be investigated. If the expected dwell time is short, identifying patients who are most likely to experience a PUSGIV failure and identifying measures to increase PUSGIV catheter survival time will become a priority.

\section{Methods}

Our primary aim was to compare the dwell time of PUSGIV and TPIV catheters, placed by nurses, to determine if there was a significant difference in length of dwell-time. To evaluate dwell time accurately, records regarding admitted patients whose length of stay (LOS) was 4 days or longer were examined. Our secondary aims were 1) to evaluate the influence of age, sex, and/or BMI on dwell time of the PUSGIV catheter and 2) to determine if specific patient populations based on age, sex, admitting diagnosis, or BMI received PUSGIV more often than others in the ED.

Review and approval was obtained from the Institutional Review Board of the study hospital prior to engaging in the study. A retrospective secondary data analysis used electronic records of patients admitted through the ED from January 2010 to 2013 to compare PUSGIV and TPIV catheters in regards to patient characteristics and catheter dwell times. Records excluded from the study included those related to pregnant patients and ED patients that were not admitted to the hospital. Due to increased BMI during pregnancy, patients admitted with a pregnancy related diagnosis were omitted from the study. Patients seen only in the ED were not selected because length of stay of ED patients is less than 24 hours.

Records of eligible cases were selected randomly from the study hospital's electronic medical record. Relevant variables were stored in an Excel database. Random selection was performed by using the random number function in Excel to assign a random number to each eligible case. Records were sorted by random number column and the first 700 cases were chosen. Cases with missing or implausible data were eliminated leaving a total of 597 cases in the sample. For instance, patients with dwell times of $>15,000$ minutes or BMIs greater than 130 were excluded from the study as the values are implausible and probably reflect keystroke errors in data entry.

For the primary aim, a total sample of only 128 with equal size groups conveys 0.80 power to detect moderate effects of PUSGIV assuming an alpha of 0.05. For the secondary aim, a larger sample size of approximately 550 was desired to capture smaller effects. A sample of $n=297$ patients who received PUSGIV and $n=295$ patients who received TPIV was established. Patient groups of equal size were selected for analytical reasons. This is not intended to imply that PUSGIV is applied to $50 \%$ of the patients in the ED. We estimate that only about $3 \%$ of ED patients receive a PUSGIV catheter.

Theoretically relevant variables, including patients age, sex, BMI, IV dwell time in minutes, and the patient's admitting diagnosis were included in the data collection. Although relevant, the length and size of catheters and anatomical placement were not obtainable from the electronic record and were not included in the study. 
Records of pregnant patients and minors were excluded. Demographic variables, such as socio-economic status, race, or insurance status that were not considered theoretical predictors of catheter dwell-time were not collected. This is consistent with US regulations for human subject's research which emphasize the collection only of data that is necessary to answer research questions.

The primary aim (to compare dwell times of PUSGIV and TPIV catheters) was evaluated by means of an independent samples t-test. The influence of age, sex, and BMI on dwell-times of PUSGIV was evaluated by means of linear multivariable analysis. Determination of the percentage of specific patient groups who received PUSGIV was done through examination of frequencies. The database was examined for missing data. Missing data was judged to be missing at random. Five hundred ninety two cases with complete data were analyzed. Multivariable modeling was performed using the SPSS 20 statistical package.

\section{Results}

\section{Comparison of Dwell-Times}

Characteristics of the sample are shown in Table 1 (SD = standard deviation).

Differences in sample characteristics between groups were apparent on initial evaluation of frequencies in Table 1, which suggested that age, BMI, and gender might predict placement of sonogram-guided IV catheters. Logistic regression analysis showed that being male resulted in being about $45 \%$ less likely to receive a sonogram-guided IV catheter (ExpB $=0.55, \mathrm{CI}=0.39$ to 0.79 ), but age and BMI were not compelling predictors for the use of sonogram guidance. This is consistent with observations that women patients in US hospitals are more likely to object to repeated venipunctures than men.

The average dwell times for PUSGIV and TPIV were significantly different $(t=-8.9 ; p<0.0001 ; \mathrm{CI}=-2511$ to -1606 ) with the TPIV surviving over twice as long as the PUSGIV. Descriptive statistics for dwell times are outlined in Table 2.

A multivariate linear regression was performed using BMI, sex, age, and PUSGIV as predictors of the dwell time of catheters. BMI, sex, age, and PUSGIV were all significantly associated with dwell time as shown in Table 3 . This model results in an $\mathrm{R}^{2}$ of 0.22 , thus about $22 \%$ of the variance in dwell time is explained by BMI, sex, age, and PUSGIV.

\begin{tabular}{|c|c|c|c|}
\hline & $\begin{array}{l}\text { Total sample } \\
\text { Mean (SD) }\end{array}$ & $\begin{array}{l}\text { PUSGIV group } \\
\text { Mean (SD) }\end{array}$ & $\begin{array}{l}\text { Tradition group } \\
\text { Mean (SD) }\end{array}$ \\
\hline Age & $56.5(17.8)$ & $53.6(16.1)$ & $60.5(18.6)$ \\
\hline \multirow[t]{2}{*}{ BMI } & $29.4(7.8)$ & $30(8.4)$ & $28.6(7)$ \\
\hline & $\begin{array}{c}\text { Total sample } \\
\text { Rounded percentage }\end{array}$ & $\begin{array}{l}\text { PUSGIV group } \\
\text { Rounded percentage }\end{array}$ & $\begin{array}{l}\text { Traditional group } \\
\text { Rounded percentage }\end{array}$ \\
\hline Female & $61 \%$ & $70 \%$ & $53 \%$ \\
\hline \multicolumn{4}{|l|}{ Admitting diagnosis } \\
\hline Cardiac & $26 \%$ & $20 \%$ & $33 \%$ \\
\hline Gastrointestinal & $10 \%$ & $15 \%$ & $4 \%$ \\
\hline Diabetes/renal & $6 \%$ & $9 \%$ & $3 \%$ \\
\hline Pulmonary & $8 \%$ & $12 \%$ & $4 \%$ \\
\hline Infection & $13 \%$ & $11 \%$ & $15 \%$ \\
\hline Neurological & $5 \%$ & $8 \%$ & $2 \%$ \\
\hline Orthopedic & $7 \%$ & $4 \%$ & $11 \%$ \\
\hline Cancer & $6 \%$ & $4 \%$ & $8 \%$ \\
\hline Miscellaneous & $19 \%$ & $17 \%$ & $20 \%$ \\
\hline
\end{tabular}


Table 2. Comparison of dwell-times (minutes) for PUSGIV and TPIV.

\begin{tabular}{cccc}
\hline & Mean dwell-time & Range & SD \\
\hline PUSGIV & 1675 (1.2 days) & $20-8767$ & 2102 \\
TPIV & 3733 (2.6 days) & $10-11,115$ & 3377 \\
\hline
\end{tabular}

PUSGIV = Peripheral ultra-sound guided intravenous access; TPIV = traditionally placed peripheral intravenous access.

Table 3. Results of multivariable analysis.

\begin{tabular}{ccccc}
\hline Variable & $\begin{array}{c}\text { Unstandardized beta } \\
\text { coefficients }\end{array}$ & t-score & p value & CI \\
\hline PUSGIV & -1443.132 & -8.06 & 0.0001 & -1795 to -1091 \\
Age in years & 24.705 & 4.8 & 0.0001 & 14.6 to 34.8 \\
BMI & -31.69 & -2.8 & 0.005 & -54 to -9.4 \\
Sex & -602.053 & -3.31 & 0.001 & -960 to -244 \\
Constant & 4973.285 & & & \\
\hline
\end{tabular}

PUSGIV = peripheral ultrasound guided intravenous access; $\mathrm{BMI}=$ body mass index .

The model may be summarized for females receiving PUSGIV as follows:

$$
\text { Dwell time }=4973.285+24.705(\text { age })-1443.132-31.69(\text { BMI })+\text { error. }
$$

For males receiving PUSGIV, dwell time can be estimated using the following equation:

$$
\text { Dwell time }=4973.285+24.705(\text { age })-1443.132-602.053-31.69(\mathrm{BMI})+\text { error. }
$$

For example, a 70 year-old female with a BMI of 29 should expect her sonogram guided IV catheter to be sustained for 4340.493 minutes (about 3 days), whereas the same female when given a traditionally placed IV catheter could expect it to be sustained for 5783.625 minutes (about 4 days) given all other factors remain the same. For an obese male, such as a 40 year-old man with a BMI of 32, a sonogram-guided catheter could be expected to last 2902.12 minutes (about 2 days). In summary, the predictive model indicates that peripheral IV access is sustained longest in older, thinner females who have their IVs placed using the traditional method rather than by sonogram guidance.

\section{Discussion}

In this study we evaluated the relationships between peripheral IV catheter placement method, gender, age, BMI, and catheter dwell-times. These factors were chosen for evaluation because they are theoretically salient and information about these factors was available. Clearly other, unmeasured factors are related to dwell-times of IV catheters as shown by the fact that $78 \%$ of the variance in dwell-times in our model was unexplained, thus falling in the error term of the equation. It was not our intention to evaluate every factor that could possibly influence the dwell-times of IV catheters, but to determine if age, gender, peripheral IV catheter placement method, and BMI were related to dwell-times.

In summary, our results revealed that catheter dwell time was significantly shorter for patients receiving a PUSGIV rather than a TPIV. The cause of the shortened dwell time for the PUSGIV catheters is multifactorial. Other factors likely to contribute substantially to dwell times include vein friability, which is over-represented in patients who receive PUSGIV due to past history of multiple medical problems and difficult IV sticks. The probability of infiltration would be greater in such patients. Poor catheter placement is another possible influence on shortened dwell-time of PUSGIV catheters. If catheters are poorly placed upon insertion, the target vein may be abraded, but not actually entered, resulting in a blood return, but not direct placement within the vein. In addition, previous studies have shown that site placement is a factor in the dwell time. The placement of the catheter in the basilic vein on the inside of the upper arm may cause the IV tubing to rub against the chest causing early dislodgement. Depth of vein may influence dwell-time, as well. When accessing deeper veins, for instance 
in obese patients, the depth of the vein requires a longer length of catheter to reach the vein. The result is a relatively short length of catheter threaded into the vein theoretically leading to easier dislodgement. Furthermore, the PUSGIV catheter may become kinked after insertion into a deep vein due to the steep angle of insertion. The kink in the IV catheter will obstruct the flow of IV fluid resulting in premature removal of the catheter.

In addition, anecdotal evidence obtained during this study indicated that the jelly applied to the skin during sonogram imaging of the site is sometimes not removed well, and in such cases, the adhesive securing the catheter does not stick, allowing the catheter to be inadvertently removed. One solution is to obtain products now available which attach to the ultrasound probe and use minimal gel, leaving a drier site that is more favorable to sustaining adhesives. Another solution is to clean the skin with alcohol or chlorhexidine swabs after catheter insertion and then wipe dry to remove the gel from the skin prior to the Tegaderm application.

The finding that older patients sustained longer dwell times was unexpected. Increased dwell time in older patients may possibly be due to elders moving less than younger patients. Logically, less movement stresses catheters less resulting in greater survival of access sites, but there is no evidence to support this assumption.

\section{Limitations}

The information obtained is limited by the usual problems associated with secondary data analysis. One of the greatest limitations of secondary data analysis is the unavailability of some types of data. In this study, extracting the few variables of interest from an electronic medical record created for clinical rather than research work was difficult and time consuming, requiring 18 months of work including locating data and writing computer code for extraction. Future research will be required, perhaps on a prospective basis, to identify and quantify other factors that were not included here. We presume the data entered into the medical record is accurate. For instance, infiltration could occur at the time of documentation or several hours earlier, but we have no way of knowing how much time elapsed between event and documentation of the event. Also, because the exact cause of the removal of the PUSGIV catheter was not available from our record review, we do not know if catheters were removed due to infiltration or because a more permanent line was intentionally placed such as a PICC or central line, or because the patient was discharged. We also were not able to extract the size of catheter placed, only that the line was placed using sonography.

\section{Conclusion}

Many patients with difficult IV access experience delay in diagnosis and treatment. PUSGIV catheters have a place in the healthcare setting by providing immediate access and treatment. However, like Dargin and colleagues, we found that PUSGIV catheters survive on average 24 hours [7]. Based on our findings, if the patient has received PUSGIV placement, we recommend practitioners begin a plan to place a more stable venous access such as PICC line, midline, or central line upon the determination that the patient will be admitted from the ED to the hospital for more than 24 hours. If the patient is critically ill, placement of a central line should occur rapidly, if possible. Also, because the PUSGIV catheters are not as hardy as TPIV catheters, frequent visualization and palpation of the PUSGIV site are imperative to identify dislodgement early. Further investigations should include the factors that influence dwell-time of PUSGIV catheters such as infusion therapy, the anatomical site of placement, length of catheter, catheter securement, and ways to increase beginning practitioner proficiency.

\section{References}

[1] INS Position Paper. Recommendations for Improving Safety Practices with Short Peripheral Catheters. https://www.learningcenter.ins1.org/

[2] American Institute of Ultrasound in Medicine (AIUM) (2012) AIUM Practice Parameter for the Use of Ultrasound to Guide Vascular Access Procedures. AIUM, Laurel, MD. http://www.aium.org/resources/guidelines/usgva.pdf

[3] White, A., Lopez, F. and Stone, P. (2010) Developing and Sustaining an Ultrasound-Guided Peripheral Intravenous Access Program for Emergency Nurses. Advanced Emergency Nursing Journal, 32, 173-188. http://dx.doi.org/10.1097/TME.0b013e3181dbca70

[4] Aponte, H., Acosta, S., Rigamonti, D., Sylvia, B., Austin, P. and Samolitis, T. (2007) The Use of Ultrasound for Placement of IV Catheters. AANA Journal, 75, 212-216. 
[5] Constantino, T., Parikh, A., Satz, W. and Fortis, J. (2005) Ultrasonography-Guided Peripheral Intravenous Access versus Traditional Approaches Inpatient with Difficult Intravenous Access. Annals Emergency Medicine, 46, 456-461. http://dx.doi.org/10.1016/j.annemergmed.2004.12.026

[6] Miles, G., Salcedo, A. and Spear, D. (2012) Implementation of a Successful Registered Nurse Peripheral UltrasoundGuided Intravenous Catheter Program in an Emergency Department. Journal Emergency Nursing, 38, 353-356. http://dx.doi.org/10.1016/j.jen.2011.02.011

[7] Dargin, J., Rebholz, C., Lowenstein, R., Mitchell, P. and Feldman, J. (2010) Ultrasonography-Guided Peripheral Intravenous Catheter Survival in ED Patients with Difficult Access. American Journal Emergency Medicine, 28, 1-7. http://dx.doi.org/10.1016/j.ajem.2008.09.001

[8] Moore, C. (2013) An Emergency Department Nurse-Driven Ultrasound-Guided Peripheral Intravenous Line Program. Journal Vascular Access, 18, 45-51. http://dx.doi.org/10.1016/j.java.2012.12.001

[9] Schub, T. and Caple, C. (2014) Peripheral Intravenous Cannula: Over-the-Needle Catheter Insertion. Nursing Practice and Skill. Cinahl Information Systems, Glendale.

[10] O’Grady, N., Alexander, M., Burns, L., Dellinger, E., Garland, J., Heard, S., et al. (2011) Guidelines for the Prevention of Intravascular Catheter-Related Infections. Centers for Disease Control and Prevention. http://www.cdc.gov/hicpac/BSI/BSI-guidelines-2011.html

[11] Fields, J., Dean, A., Todman, R., Au, A., Anderson, K. and Ku, B., et al. (2011) The Effect of Vessel Depth, Diameter, and Location on Ultrasound-Guided Peripheral Intravenous Catheter Longevity. American Journal Emergency Medicine, 30, 1134-1140. http://dx.doi.org/10.1016/j.ajem.2011.07.027

[12] Elia, F., Ferrari, G., Molino, P., Converso, M., De Fillippi, G., Milan, A. and Apra, F. (2012) Standard-Length Catheters vs Long Catheters in Ultrasound-Guided Peripheral Vein Cannulation. American Journal Emergency Medicine, 30, 712-716. http://dx.doi.org/10.1016/j.ajem.2011.04.019

[13] El-Shafey, E. and Tammam, T. (2012) Ultrasonography-Guided Peripheral Intravenous Access: Regular Technique versus Seldinger Technique in Patients with Difficult Vascular Access. European Journal General Practice, 94, 216-222.

[14] Mills, C., Liebman, O., Stone, M. and Frazee, B. (2007) Ultrasonographically Guided Insertion of a 15-cm Catheter into the Deep Brachial or Basilica Vein in Patients with Difficult Intravenous Access. Annals Emergency Medicine, 50, 68-72. http://dx.doi.org/10.1016/j.annemergmed.2007.02.003

[15] Keyes, L., Frazee, B., Snoey, E., Simon, B. and Christy, D. (1999) Ultrasound-Guided Brachial and Basilic Vein Cannulation in Emergency Department Patients with Difficult Intravenous Access. Annals Emergency Medicine, 34, 711-714. http://dx.doi.org/10.1016/S0196-0644(99)70095-8

[16] Walker, E. (2009) Piloting a Nurse-Led Ultrasound Cannulation Scheme. British Journal Nursing, 18, 854-859. http://dx.doi.org/10.12968/bjon.2009.18.14.43352

[17] Blaivas, M. and Lyon, M. (2006) The Effect of Ultrasound Guidance on the Perceived Difficulty of Emergency Nurse-Obtained Peripheral IV Access. Journal Emergency Medicine, 31, 407-410. http://dx.doi.org/10.1016/j.jemermed.2006.04.014

[18] Arbique, D., Bordelon, M., Dragoo, R. and Huckabee, S. (2014) Ultrasound-Guided Access for Peripheral Intravenous Therapy. Academy Medical-Surgical Nurses, 23, 9-15.

[19] Panebianco, N., Fredette, J., Szyld, D., Sagalyn, E., Pines, J. and Dean, A. (2009) What You See (Sonographically) Is what You Get: Vein and Patient Characteristics Associated with Successful Ultrasound-Guided Peripheral Intravenous Placement in Patients with Difficult Access. Journal Academy Emergency Medicine, 16, 1298-1303. http://dx.doi.org/10.1111/j.1553-2712.2009.00520.x

[20] Schoenfeld, E., Shokoohi, H., and Boniface, K. (2011) Ultrasound-Guided Peripheral Intravenous Access in the Emergency Department: Patient-Centered Survey. Western Journal Emergency Medicine, 12, 475-477. http://dx.doi.org/10.5811/westjem.2011.3.1920

[21] Blaivas, M., Brannam, L. and Fernandez, E. (2003) Short-Axis versus Long-Axis Approaches for Teaching Ultrasound-Guided Vascular Access on a New Inanimate Model. Academy Emergency Medicine, 10, 1307-1311. http://dx.doi.org/10.1111/j.1553-2712.2003.tb00002.x 